\title{
O FANTASMA DA REPETIÇÃO E A RELAÇÃO MÃE / FILHA
}

\section{THE PHANTOM OF REPETITION AND MOTHER/ DAUGHTER RELATIONSHIP}

Lilian Perdigão Caixeta Reis* Elaine Pedreira Rabinovich ${ }^{* *}$

Reis LPC, Rabinovich EP. O fantasma da repetição e a relação mãe/filha. Rev Bras Crescimento Desenvolv Hum 2006; 16(3):39-52.

Resumo: Este estudo de caso foi realizado com o objetivo de verificar a interferência de padrões e crenças familiares no processo de diferenciação de jovens mulheres por meio de estudo de casos. Foram selecionadas sete jovens atendidas no Centro de Orientação da Família (COF), residentes em Salvador, e que apresentavam dificuldades emocionais associadas à vida familiar. Entrevistas semi - estruturadas com as participantes, acopladas a relatórios de atendimentos, forneceram a base empírica do estudo. O conjunto das informações coletadas foi analisado agrupando os conteúdos por temas. $\mathrm{O}$ tema destacado, medo de repetir a história de vida materna, foi desdobrado em: ausência da figura paterna; falta de credibilidade quanto à figura masculina; dificuldades associadas à sexualidade e conflitos com a mãe. As jovens investiam sua energia preferencialmente no estudo e objetivo profissional, sentindo-se responsáveis por colaborar economicamente na manutenção do grupo familiar e assumindo papéis que caberiam a seus pais. A sobrecarga e dificuldade para lidar com tais situações repercutiam nas jovens, com incidência de sintomas psicossomáticos, sinalizando a dramaticidade dos conflitos vivenciados. Conclui-se que a possibilidade de emancipação aberta às novas gerações em uma sociedade urbana e individualista entrava em conflito, nos casos estudados, com o ideário ainda tradicional, onde padrões e crenças apontam para a lógica da reciprocidade e solidariedade dos laços de parentesco.

Palavras-chave: Diferenciação. Repetição. Relação mãe-filha. Jovens. Conflitos familiares.

\section{INTRODUÇÃO}

$\mathrm{O}$ atendimento psicológico a jovens mulheres fez emergir questões que nortearam o presente estudo: o desejo de se tornarem independentes de suas famílias; os conflitos com a figura materna; e a ênfase em trilhar um caminho que fosse diferente daquele feito pela mãe, devido ao receio de repetir a história da mesma, considerada difícil e sofrida, "um fantasma".

Oriundas de famílias matrifocais, a mãe aparecia como a figura de referência por ser a autoridade em casa e, conseqüentemente, com quem tinham mais dificuldade. Em alguns casos, os conflitos ocorriam devido à incompatibilidade entre as suas escolhas e o que as mães pretendiam para elas; ou quando não se sentiam ainda em condições de assumir responsabilidades pela própria vida.

A partir daí, foi preciso ampliar o olhar para além do pedido de ajuda destas jovens que não conseguiam lidar sozinhas com estas questões, direcionando-o para suas famílias a fim de conhecê-las melhor. Novas problemáticas

* Psicóloga. Bolsista E.P.I. Fapesb, Universidade Católica do Salvador.

Dissertação de Mestrado da primeira autora orientada pela segunda no Mestrado em Família na Sociedade Contemporânea da Universidade Católica de Salvador, 2003 e-mail:liliancr@ucsal.br

** Psicóloga, Universidade Católica do Salvador. 
emergiram, mostrando a necessidade de uma análise que considerasse também fatores do seu contexto de origem.

Os conflitos das jovens, ao lado de aspectos pessoais, provocaram reflexões quanto às transformações pelas quais passam as famílias brasileiras, permeadas por mudanças globais.

Como este trabalho partiu de uma prática e objetivou a reflexão desta prática, buscou teorias que pudessem vir a interligar os pontos evidenciados no atendimento clínico e em sua contextualização, seguindo, no percurso teórico, um caminho a ele correlato.

Realizou uma primeira opção teórica assumindo lidar com padrões - entendidos como regras, mitos, crenças e modelos que servem de referência para o "outro" -, e com crenças que norteiam o relacionamento entre os jovens e suas famílias, o que implicou na delimitação de dois campos principais:

1. campo do funcionamento interno familiar: referente aos padrões que regem a compreensão que os membros adquirem de sua história e dos papéis que lhe são designados, dentre outros fatores, e

2. campo da inserção da família na sociedade: referente aos padrões que explicam a existência desta família na sociedade na qual está inserida.

\section{Campo do funcionamento interno familiar}

As famílias repetem padrões ao longo de sua história, como forma de manter a estabilidade, protegendo-se de desvios e mudanças, o que pode ser positivo quando seus membros conseguem ser flexíveis e criativos, abertos à troca com o meio, buscando maior qualidade de vida ${ }^{1}$.

Estes padrões de conduta, ou indicadores de caminhos a seguir na própria vida, são sustentados e fortalecidos pelas crenças passadas de geração a geração. As pessoas dentro do grupo familiar podem ou não continuar perpetuando estas crenças, acreditando que os referenciais indicados servem como parâmetros para guiar seu caminho pessoal, principalmente na transição entre juventude e vida adulta.

Em alguns casos, a oposição e busca de mudanças liga-se a um efetivo bem-estar, principalmente quando existem padrões que, ao serem repetidos, adquirem característica negativa pois impõem aos membros da família condutas sintomáticas que acabam perpetuando situações problemáticas.

Ocorrem, então, situações nas quais os padrões que regem uma família são discordantes dos pressupostos externos, gerando estresse e provocando situações de conflito.

A teoria sistêmica de família enfatiza que mudanças em uma das partes do sistema familiar acarretam mudanças em outras partes ${ }^{1}$ Nesta medida, pode-se supor que mudanças nos papéis e padrões dos jovens ocasionam mudanças no sistema familiar. Um conceito bastante utilizado pela teoria sistêmica é o de diferenciação, proposto por Murray Bowen ${ }^{2}$. Define o processo de diferenciação, na análise dos sistemas familiares, como a capacidade para o funcionamento autônomo, estendendo, assim, o enfoque da pessoa ao contexto familiar. $\mathrm{O}$ oposto à diferenciação é a fusão, que indica dependência, aglutinação e indiferenciação.

Segundo esse autor, pessoas diferenciadas conseguem ter consciência de si, opiniões próprias, capacidade de decisão, conseguindo darse conta de seus sentimentos e pensamentos e, cientes de suas crenças, agir conforme estas.

$\mathrm{Na}$ fusão, estas capacidades ficam limitadas pela dificuldade da pessoa de distinguir seus sentimentos de seus pensamentos, bem como selecionar o que é próprio de si mesma do que assimila do outro. Para que a pessoa consiga alcançar sua autonomia, elaborando adequadamente seus sentimentos em relação ao grupo familiar, esta ansiedade precisa ser compreendida e, para isto, a sua história familiar deve ser enfocada, pois padrões e crenças sobrevivem por várias gerações, e com conseqüências ininteligíveis para a mesma.

Assim, o relacionamento entre mãe - filha durante o período de transição da juventude à vida adulta diz respeito à interação entre ambas, tanto no que se refere a como cada uma concebe o significado desta relação quanto às questões que advêm da cultura da família.

Estudos sobre este tema focalizaram, em sua maioria, o processo de desenvolvimento de jovens do sexo masculino. Por outro lado, autores sinalizam que existem peculiaridades no processo vivenciado por jovens do sexo feminino, pouco evidenciadas nas teorias e, às vezes, negligenciadas ${ }^{3,4,5}$. 
À jovem que manifesta o desejo de independência, sobrepõem-se condições impostas pela família e por seu meio. Haveria uma tendência a se predestinar o caminho das filhas, como se estas não pudessem ter alternativas fora do horizonte doméstico, ou que não correspondessem às expectativas de suas mães ou avós, e a concepção de um destino infeliz se não seguirem tal predestinação.

Eliacheff e Heinich ${ }^{4}$ identificaram questões pertinentes a este vínculo a partir de três eixos: o das posições da mãe; o das relações mãe - filha; e o temporal das idades, que situa o momento de vida da filha.

O risco nestes vínculos é a presença de situações em que um fator extremo determina a forma como a relação se constrói. Algumas atitudes maternas podem ser mais valorizadas do que outras; por exemplo, mães super-cuidadosas tendem a ser socialmente mais aceitas, o que minimiza os riscos decorrentes deste tipo de vínculo quando, em nome de um zelo, limita-se a capacidade da filha de expressar seus próprios desejos e conquistar sua autonomia. Da parte das filhas, dificilmente confrontam ou questionam as intenções de mães tidas como "quase perfeitas".

Nessa dimensão do cuidado, aparece também a situação de cumplicidade que sinaliza, na sociedade moderna, a confusão entre o papel de mãe que deve ser figura de autoridade, daquela que é amiga e cúmplice da filha, gerando o equívoco da mãe que tem a pretensão de substituir o papel que deveria ser ocupado pelas amigas da filha.

Em outro extremo, desponta o exemplo da mãe dominadora que, com a intenção de proteger a filha, acaba por se apossar de seus pensamentos e desejos, impondo um modelo ao qual a filha deve se conformar.

A relação entre ambas pode ficar ainda mais comprometida quando há a ausência de um terceiro, o que diz respeito também à ausência de uma autoridade paterna, o que interfere no processo de diferenciação e identificação destas jovens, favorecendo a onipotência materna.

Eliacheff e Heinich ${ }^{4}$ ressaltam que, em famílias monoparentais, muitas vezes a relação das filhas ocorre exclusivamente com a mãe. Além disso, com a privação de recursos ou de contato com o exterior, ficam restritas à sua casa e, quando adultas, têm dificuldade de sair, embora reconheçam que essa permanência impõe condições de sofrimento para si mesmas.

As filhas também costumam ocupar uma função financeira, quando conseguem alcançar um patamar de crescimento um pouco melhor, tanto pelo estudo como pelo trabalho, passando a assumir responsabilidade de mantenedoras do grupo familiar.

Além desses aspectos que caracterizam o vínculo mãe-fillha, essa relação é afetada pelas circunstâncias do processo de amadurecimento da jovem, o que nos levou a procurar uma maior aproximação com a situação que de fato vivenciam, procurando analisar o vínculo entre a pessoa e o meio.

\section{Campo da inserção da família na sociedade}

A literatura aponta ser esperado que os jovens tenham desenvolvido a capacidade de se relacionar consigo mesmo e com os outros, diferenciando-se de sua família, através da elaboração da separação dos pais, e dos grupos de referência; conquistando maior independência, autonomia e responsabilidade, afirmando sua própria identidade, tornando-se um 'eu' 3,5,6,7.

Através do discernimento de seus próprios valores, ainda que de forma confusa, podem posicionar-se quanto às suas escolhas, objetivos de vida pessoais e construir perspectivas de futuro.

Sarti ${ }^{5}$ aponta que os conflitos em decorrência da busca de uma individualidade são fenômenos das sociedades modernas. Segundo ela, para jovens de famílias pobres, a questão da autonomia adquire outro significado, pois estão sujeitos à lógica tradicional em que a solidariedade dos laços de parentesco e vizinhança determina suas posições. Prevalece a tendência maior destes jovens de conceberem seus projetos guiados pela subordinação social, em detrimento de seus interesses pessoais.

$\mathrm{Na}$ situação atual da juventude brasileira podem ser identificados fatores considerados críticos e que afetam o seu processo de desenvolvimento: o desemprego, a permanência em empregos informais e sem vínculos empregatícios; a 
gravidez precoce, o contexto de violência dos bairros mais carentes, a prostituição, as drogas, etc.

$O$ respeito ao jovem como cidadão implica no acesso à saúde, educação, moradia e condições adequadas de trabalho ${ }^{8}$; no entanto, fica excluído por não atender aos critérios de acessibilidade impostos pelo modelo de proteção social que privilegia aqueles que estão inseridos no mercado formal.

O empenho para sair da condição de exclusão torna-se um esforço pessoal e solitário, pois são recentes as políticas públicas com incentivos para o jovem empreendedor $9,10,11,12$.

A dificuldade em alcançar uma ascensão, devido à falta de acesso aos bens sociais e à baixa escolaridade, é confundida com baixa auto estima e com incapacidade intelectual, gerando constrangimentos e sentimento de vergonha. Com isto, os jovens tendem a permanecer no mesmo padrão de vida de seus pais.

Investir na educação, focalizando o desenvolvimento de competências, capacidades e habilidades, através do reconhecimento do potencial pessoal, acrescido de incentivos para projetos de vida dos jovens, viabiliza a visão de um futuro no qual possam ser protagonistas no mundo ${ }^{10}$.

Em síntese, as construções teóricas que tratam da etapa da juventude podem ser situadas em três pilares: autonomia, identidade e independência, conceitos, contudo, abertos a interpretações sócio-históricas além de implicações psicológicas.

Estes elementos, que dizem respeito à condição dos jovens dentro do contexto social, são significativos na imposição de padrões de vida para as famílias.

Há um momento, contudo, no qual o limite do que é viável dentro do contexto familiar vai de encontro aos modelos privilegiados pela sociedade, que também busca definir a existência desta família, ampliando-a sócio-econômica e culturalmente, delineando a transição entre a tradição e a contemporaneidade. Surgem, então, modelos de família, situadas entre o modelo patriarcal tradicional, e aquelas que vão se constituindo a mercê das novas alternativas contemporâneas ${ }^{13}$.

Kagitcibasi $i^{14}$ mostra que, em culturas com base coletivista, as transformações econômicas e sociais causam reflexos no processo de autonomia pessoal, exigindo adaptações, mas a interdependência psicológica com a família continua sendo valorizada, sem impedir a adequação às exigências modernas.

Estudos de sociologia da família procuram avaliá-la como uma instituição que faz a mediação entre o indivíduo e a sociedade, evidenciando sérias conseqüências quanto a mudanças em nossa sociedade e nas estruturas das famílias brasileiras, repercutindo diretamente no processo de inserção social dos jovens ${ }^{15,16}$.

Distinguindo como aspectos principais das relações internas de seus membros aqueles relativos à divisão de papéis, poder e autoridade; e como preponderantes nas relações externas, os referentes à vida social (vida comunitária, trabalho, política, estado), Petrini ${ }^{16}$ mostra que a família ocupa, dentro da sociedade, funções educativas, afetivas e sociais. Destaca, também, que cabe à família transmitir valores que passam de geração para geração, que vão ser a base para a construção de laços afetivos, de solidariedade, de construção de vínculos entre as gerações, e principalmente, de identificação sexual.

Porém, há grande diferença na forma como estes aspectos se manifestam na estrutura familiar, ocorrendo variações devido às influências regionais, éticas e sociais, mostrando que, no Brasil, a diversidade de padrões familiares converge para a tradição histórica nacional ${ }^{15,17,18}$.

Nas famílias matrifocais, por exemplo, o fator de distinção é a prioridade no vínculo entre mãe - filho, ou entre irmão e irmã, com menor relevância para o laço conjugal, caracterizando um sistema de parentesco, em que o poder feminino é garantido por laços afetivos ligados à função materna, e que colaboram para manter a unidade do grupo familiar. A tarefa de cuidar da família é delegada à mulher, e aos filhos, que acabam por tornar-se o braço direito das mães 5, 16, 19, 20 .

Nestes casos, o papel do homem como provedor e autoridade masculina que, tradicionalmente, caracterizaria o respeito e a moral da família, indicando uma qualidade de gênero, fica abalado e é comprometido cada vez mais pelas mudanças na organização das famílias ${ }^{4,17,18,21,22}$.

Outro dado relevante é o aumento dos arranjos familiares formados por um dos cônjuges com um filho, os monoparentais, identificados mais pelo critério de unidades domésticas do que por um sistema familiar. Nestes, prevalece chefia 
feminina (censo de 1995) constituída por mulheres jovens, com menos de 40 anos, sobretudo mães solteiras, pobres, e que ainda vivem em domicílios com outros parentes ${ }^{23}$.

Conforme apontado por Forbes ${ }^{21}$ :

O Brasil tinha uma sociedade hierarquizada e vertical, com uma presença muito forte do pai ou do chefe. Essa sociedade não existe mais, o que deixa as pessoas perdidas, levando a novas doenças e a novas soluções. Tanto o saber quanto o próprio pai viraram genéricos, ou seja, não há mais padrão para nada. Sem a figura do mestre, o homem "desbussolou-se".

$\mathrm{O}$ apoio para manter a representação da moral masculina é encontrado na complementaridade do grupo consangüíneo por meio da rede de parentesco, e pode ser substituído pelo avô materno, pelo irmão da mãe, ou pelo filho primogênito ${ }^{4,17,18,21,22,24}$.

Estas mudanças na constituição das famílias, permeadas pelas questões sociais e culturais, afetam diretamente a vida dos indivíduos, e vão definindo posicionamentos para estes. O que gera contradição entre um discurso contemporâneo, no qual se defende a lógica da individualidade, confundida com a ruptura familiar, e a realidade, que impõe à pessoa escolhas voltadas para a necessidade de responder aos laços familiares, afetando imensamente a concepção de futuro que os jovens poderiam elaborar.

A lógica da reciprocidade em contraposição a uma lógica individualista estaria, portanto, sustentando conflitos entre gerações e, mais do que isto, apontando para rupturas.

A fim de confrontar estes estudos com a prática clínica, recorremos ao estudo de casos, com o objetivo de analisar as interferências dos conflitos com a família, no processo de diferenciação das jovens.

\section{MÉTODO}

A pesquisa foi realizada por meio da análise qualitativa de dados sobre a vida de sete jovens atendidas pela pesquisadora, por aproximadamente dois anos (de setembro de 2000 a dezembro de 2003), no Centro de Orientação da
Família - COF, que funciona no bairro de Novos Alagados, região do subúrbio de Salvador, Bahia.

A escolha das jovens para este estudo ocorreu a partir dos seguintes critérios: faixa etária entre 18 e 30 anos no período da pesquisa (por corresponder à idade das pessoas inseridas no grupo); participação em atendimentos individuais e no grupo com a pesquisadora; freqüência aos atendimentos; disponibilidade para oferecerem informações. A faixa etária foi selecionada devido às jovens não apresentarem diferenças dentro dessa faixa quanto ao tema do estudo.

O trabalho foi desenvolvido através de estudos de caso longitudinais, por meio da análise de entrevistas semi - estruturadas (anexo I) e dos relatórios de atendimentos da equipe do $\mathrm{COF}$. $\mathrm{O}$ conteúdo das entrevistas foi organizado em torno de eixos temáticos sugeridos pelas falas das entrevistadas, gerando a construção de categorias para análise.

Estas jovens passaram, inicialmente, por atendimentos individuais com a assistente social (especializada em terapia familiar), e com a psicóloga. Familiares foram convidados para atendimentos, a pedido das jovens, nos casos em que a mediação fez-se necessária, para lidar com situações de conflitos. Conforme a especificidade de cada caso, estas entrevistas foram realizadas ora pela assistente social, ora com a psicóloga; e em alguns casos, em conjunto, com a jovem e seus familiares. Algumas mães foram indicadas para serem acompanhadas por outra psicóloga da equipe.

Três das jovens residiam em comunidades do subúrbio, próximas à sede do $\mathrm{COF}$, na região mais carente de Salvador; duas, em outros bairros carentes da região central, e duas em bairros de classe média. Chegaram a este centro espontaneamente, através da indicação de amigas ou por meio de divulgação na imprensa.(Anexo II).

A consulta a documentos, como entrevistas e relatórios de atendimento, organizados em prontuários, com acesso restrito aos membros da equipe, foi realizada com a autorização das pessoas atendidas e dos responsáveis pelo projeto.

Foram selecionados, a partir das falas, os temas que correspondiam ao objetivo da pesquisa, analisados com o suporte das teorias apresentadas anteriormente e organizados por categorias que favoreciam a compreensão da dimensão pessoal 
e familiar, além da contextualização sóciocultural dos casos.

\section{RESULTADOS E DISCUSSÃO}

\section{O fantasma da repetitividade - o medo de repetir a história de vida materna}

Fantasma ${ }^{+}$é aquilo que amedronta, imagem ilusória, sob forma indefinida que apavora, só de pensar no seu suposto reaparecimento ${ }^{25}$.

O fantasma que mais ronda a vida das jovens é aquele da história de vida da figura materna. Verbalizado como conteúdo de preocupação por parte de mães, avós e jovens, muitas vezes é tratado como assunto pelas famílias. Este fantasma se evidencia em temas como: namoro, vivência sexual, estudo, trabalho, escolhas pessoais, sofrimentos, solidão, etc.

Nele, um fato vivenciado pela mãe tornase decisivo para a formação da filha, servindo de referência para os critérios de sua educação, excessivamente rígidos em alguns casos, muito tolerantes em outros.

O peso da história materna marca, assim, definitivamente a vida das filhas, e gera, conseqüentemente, situações que podem causar conflito.

\section{Relação conflituosa com a figura materna}

A relação conflituosa com a figura materna é acentuada quando há uma exigência de mudança do percurso da história, a fim de não seguir um script que se aproxime do passado materno. Percebe-se o empenho das jovens em fugir do modelo materno, lutando para "provar" para a família que podem conseguir fazer um caminho diferente.

Subjacente a essa dinâmica estava rejeição a atitudes da mãe, negação de sua maternidade ou censura de suas escolhas; o que gerava vergonha ante qualquer sinal que indicasse aproximação com o modo de ser materno, concomitantemente a sentimentos confusos devido à mistura entre raiva e admiração:
"Hoje sei que minha mãe tava errada. Mas não consigo ter raiva dela. Tenho meus valores, sei que quero ser diferente dos meus pais. Aprendi desde pequena a ser muito responsável... acho que por tudo isso". (Mary, 2001).

"Minha mãe sempre gostou de festas, farras. Já teve vários companheiros. Minha avó diz que ela é quem mais deu trabalho pra ela. Passei a vida toda vendo isso... Sofri muito... Eu sou a filha mais velha, tive que ajudar minha avó a cuidar dos meus irmãos..." (Joana, 2002).

Ocorria também a suposta inversão de papéis, com queixas das jovens por ter de assumir funções e tarefas que seriam de competência da mãe, ao substituir os pais na organização da casa, mesmo conscientes de que exageravam tomando para si obrigações além do devido.

As situações de conflito identificadas mostraram que nem sempre o problema nasce da relação direta entre mãe e filha, o que inviabiliza querer explicá-lo pela culpa de uma ou outra. Circunstâncias da vida geraram interferências na convivência destas, e comprometem não só o vínculo entre ambas, mas direcionam a estruturação da família.

Nos casos em que as mães mostraram-se impossibilitadas de assumir seu papel, entrou em cena a figura da avó materna que, pelo menos durante a primeira infầncia, tornou-se responsável pelos cuidados e educação das jovens, o que provavelmente lhes forneceu o suporte para conseguirem se posicionar diante das atitudes das mães:"recebi educação esmerada, mas minha avó era linha dura, ali ó...". (Adélia, 2002).

As avós foram vistas como presenças fortes, a mão firme que não deixa a casa desmoronar, seja pelos valores que transmitem, ou por desempenharem a função de mantenedoras do grupo familiar. Acabavam suprindo carências da função da mãe, o que conseguiam pelo menos do ponto de vista afetivo, tornando-se pessoas significativas para estas jovens. Ao falar da morte

\footnotetext{
${ }^{+} \mathrm{O}$ termo fantasma tem sido usado pela psicanálise em outro sentido, não utilizado no presente estudo onde tal termo é usado em seu sentido do senso comum.
} 
da avó Mary conta que "a familia se perdeu a partir dai".".

A gravidez precoce foi um dos principais temores destas avós, já que as netas eram prova concreta de que as filhas engravidaram na adolescência ou juventude. Percebe-se, então, que a família projeta nestas jovens a preocupação de que possa identificar-se com a mãe. Nestes casos, o exemplo da mãe tem conotação negativa.

O modelo da avó prevalecia; sua presença era considerada como algo positivo, mas encerrava estas jovens numa triangulação feminina. Durante a infância e adolescência se viam cercadas por um círculo composto principalmente por mulheres, a figura masculina raramente aparecendo nesse contexto ou, ao aparecer, esvaziado de força.

Destaca-se a importância da ausência paterna, sempre evidenciada nos relatos de quatro jovens que não conheceram seus pais, ou conviveram pouco com eles. $\mathrm{O}$ desejo de aproximação ao pai é explicado tanto por uma necessidade de ser aceita e amada por ele quanto pela possibilidade de responder a dúvidas sobre sua origem; e ainda pelo entendimento de que, na presença de um pai, não ficariam tão sobrecarregadas e nem tão comprometidas com a ajuda às mães.

Já as jovens que tinham o pai, percebiam estes como homens enfraquecidos ou omissos, vítimas do alcoolismo e desemprego, dando mais trabalho do que ajuda: "Meu pai diz que eu sou a aposentadoria dele." (Dayane, 2002).

Em apenas um caso, o pai foi identificado como machista e autoritário, gerando revolta e aversão a certas atitudes paternas.

Os pais existiam o tempo todo no imaginário das jovens que, atentas à sua fragilidade real, ou à ausência sofrida a vida inteira, reconheciam que a sua falta as colocava em situação mais delicada diante de suas mães.

A posição que estas jovens tomaram diante desta ausência gerou confusão em relação aos papéis que deviam ocupar na relação com a mãe. Esta situação pode levá-las a atitudes extremadas, de quase substituir o pai como parceiro, ou de substituí-lo como mantenedor da casa.

Ocorreu ainda a preocupação de não deixar a mãe sozinha, sobressaindo um sentimento de que estas, já abandonadas uma vez, e tão solitárias atualmente, não suportariam a ausência das filhas. Esta percepção inibia as filhas na busca de outros vínculos, mantendo-as excessivamente apegadas às mães, o que se acentuava para aquelas que não tinham convivência com o pai.

\section{Desconfiança em relação ao sexo oposto - solidão e silêncio}

Destaca-se nos relatos, o tema da solidão, que abrange vários outros aspectos: temores em relação ao sexo masculino, visto como responsável pelo sofrimento materno; a solidão vivenciada pela mãe e o medo da filha de tornar-se pessoa tão só quanto sua mãe; o medo de engravidar; o sentimento da filha de ter que compensar a solidão materna.

Os homens foram vistos como irresponsáveis por não terem assumido compromisso com as mães. Houve reforço, por parte de avós e mães, de que os homens não mereciam confiança, pela situação de abandono na qual deixaram suas companheiras. Esta ênfase das famílias provocou uma visão preconceituosa quanto ao sexo masculino, com a reação de evitar o convívio com pessoas do sexo oposto: "Não admito ser traida ou enganada, e devido a isso me decepciono com facilidade com as pessoas."(Mary, 2001).

Deste tema emergiram preocupações quanto à sexualidade, o que implicou em abordar a questão da virgindade, principalmente porque ainda se encontravam nesta condição numa sociedade que reforça a liberdade sexual, causando incômodos.

De início, houve uma manifestação do alívio pela possibilidade de expressão dos seus verdadeiros sentimentos em relação ao sentido da sexualidade, e às barreiras decorrentes dos medos, das pressões familiares e da dificuldade para assumir esta realidade diante dos rapazes ou colegas da faculdade.

Mas, ao aprofundar os motivos que as levavam a esta escolha, ficou evidente um desejo de mudança, atrelado a forças "invisíveis", que as impediam de se mover neste sentido:

"Minha mãe tá ficando doente, porque estou namorando. Disse que a estou con- 
trariando muito. Fico dividida. Meu namorado acha que ela é exagerada. (...) Ele ta insistindo para que eu vá na casa dele, não tenho coragem". (Dayane, 2002).

O medo de engravidar foi identificado como impedimento para querer namorar, já que correspondia à história de sua vida, à sua origem. Principalmente para aquelas que foram fruto de um relacionamento esporádico (gravidez não planejada), e que cresceram ouvindo esta história, o temor refletiu-se na atitude de evitar qualquer envolvimento com rapazes:

"Minha mãe acha que eu ainda não estou em idade de namorar, que tenho que terminar meus estudos primeiro. Ela não quer que eu faça o que ela fez, casando-se muito jovem... mas eu acho que já tô sim..." (Dayane, 2002).

O trabalho em grupo, por ser um ponto de encontro de pessoas com histórias parecidas, permitiu que falassem de seus incômodos (vergonha de assumir sua condição de virgindade, perante namorados e colegas), de situações de preconceito vivenciadas, da pressão e invasão de suas famílias em suas decisões mais íntimas, dentre outras.

No grupo puderam expressar sua intimidade, clareando o sentimento de solidão vivenciado, e que não podiam expressar em casa, pelo temor de magoar suas mães.

As implicações desta solidão refletiam-se no apego destas jovens às suas mães, como se tivessem que compensar, com sua presença, o sofrimento passado por elas. Contraditoriamente, empenhavam-se com zelo, dedicando a maior parte de seu tempo aos cuidados das mães, principalmente se estavam adoentadas, abrindo mão de compromissos e interesses pessoais em prol de ficar em casa, fazendo companhia para estas. Mesmo aquelas que supostamente estavam em pé de guerra, ficavam à espreita, num cuidado silencioso, atentas aos mínimos detalhes, para suprir as necessidades de suas mães, e sofrendo com a falta de reconhecimento destas.

$\mathrm{Na}$ reflexão sobre esta aproximação entre solidão e distanciamento dos rapazes, emergiu também a preocupação com o futuro, e com a possibilidade de talvez não constituir suas próprias famílias, pois viam na solidão atual de suas mães, a fatalidade da solidão para si mesmas, sofrendo em dobro no momento, antecipando a dor que presenciavam e da qual não podiam falar.

Diante desta realidade que lhes fora imposta, ficavam silenciosamente recolhidas, guardando para si seus sentimentos, uma vez que não encontravam interlocutores com os quais se sentissem livres para se expressar, o que possivelmente agravava seu sofrimento.

O acompanhamento terapêutico e a participação nos encontros de grupo tornou-se oportunidade na qual puderam expressar tais questões e, de alguma forma, aliviar esta dor, saindo da postura de silenciosas observadoras, para resolutas defensoras de suas posições, verbalizando seus argumentos, idéias e desejos: "Já estou com 26 anos, tá na hora de seguir meu caminho..."(Joana, 2002).

Porém, havia ainda um sentimento de impotência, de incapacidade de sair desta situação atual, devido às dificuldades para namorar, seja pela falta de oportunidades, pelo receio de aproximação com os rapazes, ou por imposição das mães. Em conseqüência, apareciam sentimentos de menos valia, complexos, insegurança, timidez, que corroboravam para desenvolver atitudes de recolhimento e reserva.

Tal energia acumulada precisava de válvulas de escape, e o empenho nos estudos e trabalho apareceu como justificativa, direcionando suas forças para alcançar sucesso nestas áreas, mais aceitável socialmente.

\section{Sobrevivência familiar}

Ser arrimo de família foi outro aspecto de grande repercussão na vida destas jovens, justamente por estarem estudando e trabalhando, o que gerava uma expectativa, por parte de suas famílias de que elas fossem garantia de um futuro melhor para todos.

Cinco delas residiam em bairros considerados entre os mais carentes de Salvador, identificados como áreas de risco e de muita marginalidade. E, mesmo neste contexto, conseguiram chegar à universidade, o que as inseria em grupo privilegiado.

Primeiramente, porque em suas famílias não existiam pessoas com o mesmo grau de formação; depois, porque estudaram em escolas 
públicas; e, finalmente, porque venceram graças ao esforço e vontade pessoais.

A suposta ascensão de status atribuída ao estudo evidencia que, mesmo dentro de contextos não favorecedores, encontram-se jovens que conseguem caminhar, fazendo escolhas que poderiam ser consideradas mais "competentes", do ponto de vista das alternativas existentes em sua realidade de origem. $\mathrm{O}$ estudo tornou-se a sua tábua de salvação, abrindo às vezes possibilidades ocupacionais um pouco melhores, comparadas à realidade de sua área, mas, por outro lado, deixando-as vinculadas à família pelo aspecto financeiro, por colaborarem para a manutenção e sobrevivência desta: "Minha avó quer que eu assuma a escola, ela não compreende que quero seguir outro caminho" Joana (2003).

Por este motivo, as famílias interferiam nas escolhas das jovens e, às vezes discordavam: "Todo mundo queria que eu estudasse, agora que comecei criticam minha escolha" (Aparecida, 2002). Contraditoriamente, nem sempre as famílias entendiam o esforço das jovens e seu interesse pelo estudo, além dos sofrimentos que estas vivenciavam para levar adiante suas metas.

Por trás do esforço para com os estudos, escondem-se problemáticas oriundas dos seus bairros, e expressas como o medo da violência, do desemprego, e o preconceito por serem desta ou daquela comunidade, com a discriminação no meio universitário por sua condição de pobreza, por serem negras ou de determinado bairro:

(...) Lá em casa não tem nada pra comer, minhas colegas queriam ir lá para casa, porque fica perto do carnaval, mas não posso convidálas (...) A gente tá comendo de marmita (...) (Dayane, 2001).

O desejo de alcançar uma condição de status, que vá além da condição de suas famílias de origem, pôde ser visto como um fator que motiva estas jovens, o estudo proporcionando-lhes esta distinção, aproximando-as de "outros mundos".

Contudo, o estudo emerge também como meio para adquirir maior compreensão da situação de exclusão de suas famílias, evocando um sentimento de compaixão.

Provavelmente, a condição de estarem solteiras e sem filhos, e o forte vínculo de dependência com suas mães, acrescido do sentimento de gratidão, coloca-as como que obrigadas a privilegiálas como objeto de cuidado. Novamente, a ausência do pai, como provedor, recai nas costas das filhas, vítimas desta realidade que não depende de sua escolha. No entanto, a necessidade de substituir responsabilidades paternas, contribuindo para a sobrevivência de suas famílias, destacou-se em seus discursos, como preocupação pelo bem-estar dos seus familiares, e dor pelo sofrimento no qual se encontravam, apontando para o sentimento de solidariedade, de pertencimento e consciência de que estavam em condição melhor, no momento, do que os outros membros do grupo familiar.

Ao optar conscientemente pelo cuidado com os seus, revelam uma atitude bem diversa do individualismo, prevalecendo a consciência do valor do outro, do bem comum, que supera a lógica do cada um por si.

Esta situação sobrecarregava as jovens, impondo-lhes responsabilidades que não deveriam ser de sua competência, o que, em alguns casos, provocou situações de estresse.

\section{Quando a pressão vai além da conta - situações de adoecimento}

Observou-se a incidência de quadros como ansiedade, depressão, e compulsão nos relatos das jovens e de seus familiares. Existem estudos que apontam para estes sintomas como manifestação da dificuldade da pessoa de fazer escolhas ${ }^{5,10}$.

Convém ressaltar que, nestes casos, a questão da sintomatologia pode ser inserida como parte da tendência à repetição, já que a condição de adoecimento é característica das mães, e é apresentada pelas filhas, nem sempre com o mesmo sintoma, mas compondo um quadro com sinais de depressão ou ansiedade: "problemas crônicos, não sai sozinha; tem um quadro com sintomas, dores nas pernas, pressão alta e depressão" (Adélia, 2005).

A repetitividade na similaridade entre sintomas pessoais e sintomas da mãe, pode confirmar que os sintomas identificam o sistema emocional familiar ${ }^{26}$, e podem ter sido aprendidos por meio da identificação com as mães:

"Mãinha já tem muitos problemas de saúde por causa do peso. E também para sair 
de casa, para trabalhar. Já não consegue sair sozinha, tem sempre que ir alguém com ela. Fica cansada, não pode andar muito... já tenho esta tendência por parte de mãe...". (Mary, 2002).

Em seus estudos, Bowen² comprovou que o filho que mais adoece pode ser também o mais fusionado e indiferenciado, objeto das triangulações ou projeções dos pais, levando-o a agir de maneira infantilizada, devido à dificuldade de posicionar-se adequadamente diante dos pais, ou por estar muito envolvido com as tensões entre estes ${ }^{26}$.

Estas jovens, por serem filhas únicas, ou pela posição que ocupavam em relação aos irmãos, foram investidas desta sobrecarga emocional, pelo apego com a figura materna, na fusão com a mãe ou avó.

Foi possível observar que as mães que acolheram o movimento das filhas, envolvendose no tratamento, e disponibilizando-se a um cuidado pessoal, mostraram uma maior capacidade de abertura, e contribuíram para a superação dos conflitos, favorecendo o enfrentamento destes.

Nas entrevistas posteriormente realizadas, constatou-se ter havido mudanças na forma de enfrentamento das dificuldades com valorização dos vínculos de amizade e namoro (Adélia, Dulce, Mary, Dayane), com um maior diálogo com familiares e colocação mais firme em relação a posturas discrepantes dos pais.

"Comecei a dizer a painho e mãinha que a responsabilidade é deles... agora eles que fazem mercado... continuo pagando as contas... mas não preocupo quem vai fazer... tem hora que digo que tô sendo ruinzinha com eles... não a responsabilidade é deles..." (Mary, 2005).

Nos casos de Adélia, Dulce e Aparecida percebeu-se movimento de ir ao encontro do pai, acolhendo-os como são, mantendo relacionamento com irmãos paternos ncontra a vontade de suas mães.

Adélia foi ao interior visitar o pai doente, este veio a falecer pouco tempo depois de sua visita; atualmente, mantém contato com os irmãos.

Joana retomou relacionamento com a mãe, e está construindo uma casa para si, em cima da casa desta:
"Minha mãe biológica fez de tudo para sobreviver, sempre sobreviveu das coisas que fazia, que criava, e nunca teve um emprego (...) Minha mãe prá mim é como minha irmã (...) Comecei a refletir sobre tudo que minha mãe passou, nos anos 70, mãe solteira naquela época era desvalorizada..."

Estes movimentos poderiam ser considerados apenas como próprios da etapa na qual se encontravam; no entanto, o trabalho terapêutico, inclusive com familiares, foi crucial para favorecer mudanças de atitudes que privilegiaram o diálogo intergeracional, e o enfrentamento conjunto dos problemas, fortalecendo as jovens e suas famílias, ajudando-as a se capacitar para lidar com as adversidades impostas pelas mudanças sociais.

\section{CONSIDERAÇÕES FINAIS}

O ponto de partida desta pesquisa foi o foco abordado com ênfase nos relatos de jovens que expressavam sua necessidade de se tornarem independentes, mas sem conseguir realizar este objetivo, o que as levou a procurar ajuda.

Atitudes de proteção das mães ou de outros familiares, o cerceamento próprio da realidade de uma área de risco, além da falta de recursos e acesso a serviços básicos agravaram a condição de dependência destas jovens. Para elas, sonhos próprios da juventude foram considerados como utópicos ou impossíveis. Sentiamse inibidas até para afirmar que eles ainda existiam, pois temiam ser julgadas e criticadas por tamanha pretensão.

Nesta condição, contrapondo-se ao desejo de lutar e empenhar-se na realização de suas metas, instaurou-se uma postura de desistência, de quem cruza os braços e deixa o tempo passar, aguardando que outros indiquem os passos a serem dados, limitando-se a repetir a mesma história de tantas outras mulheres da área, tendo, como exemplo principal suas mães.

De fato, mães e avós que aparecem como mulheres guerreiras, fortes e trabalhadoras e, com o suor de seu trabalho, tornaram-se sustentáculo para suas famílias, existem como figuras incontestáveis de referência. Neste meio, os homens são 
vistos mais como vilões do que como companheiros, tidos como não confiáveis, ou tão ausentes que pouca significância tinha quando se trata da educação das filhas. Mas, para as filhas, estes pais desconhecidos ou distantes marcam presença, mesmo que simbólica, porque existem.

Constatou-se que, nestas famílias em que a vida é regida pelo modelo materno, as jovens são criadas em um padrão rígido e que adquire certas especificidades de uma comunidade de baixa renda: a divisão de tarefas; o assumir responsabilidades que caberiam aos pais; o abandono do estudo; ou o apego excessivo a este como perspectiva de não ficarem limitadas a trabalhos operacionais dentro da área em que residem, etc.

Muitas jovens revelaram, em seu discurso, que as mães temem que estas repitam suas histórias pessoais, seja de fracasso nos relacionamentos, ou insucesso profissional, interferindo assim em suas decisões pessoais, e procurando direcionar suas escolhas.

Os vínculos entre mãe-filha, e destas com a família extensa, mostraram a interferência de aspectos emocionais no processo de diferenciação das jovens, revelando que as forças afetivas são significativas quando se trata de compreender a transmissão de padrões e crenças dentro do sistema familiar, perpetuando-se de uma geração para outra, influenciando escolhas pessoais.

No entanto, diversos elementos nos relatos de história de vida revelaram que aspectos sócioculturais são constitutivos para entender a complexidade dos fatores que promovem o desenvolvimento da autonomia e independência das jovens. Temas como a ausência do pai, depreciação das figuras masculinas, sobrevivência familiar, importância do estudo e trabalho, dentre outros; indicaram que as mudanças sócio-culturais afetaram diretamente suas vidas.

Apesar disto, o apego à família e seus valores foi visto como fator de sobrevivência, mesmo dentro de um ambiente conflituoso. Para estas jovens, a família existe como porto seguro, ainda que com todas as suas contradições.

Nesta lógica, prevalece a decisão de permanecer junto a suas famílias, valorizando as metas coletivas, em detrimento de projetos individuais. Este tipo de decisão não quer dizer que necessariamente estas jovens estão fusionadas, ou que não alcançaram sua diferenciação. Supõe, pelo contrário, que a capacidade de discernimento quanto às condições de vida na sociedade atual convidam mais à união de forças do que à lei do cada um por si.

Aprender a conviver com os seus, elaborando suas dificuldades, aceitando limites pessoais, parece valer a pena em prol da convivência comum e da construção de projetos familiares que, de alguma forma, sustentam e mantêm a expectativa de um futuro melhor.

\begin{abstract}
The current investigation, conducted through case studies, aimed to verify the interference of family standards and beliefs in the process of differentiation of young women. The group was composed of seven young women, all of them attending the COF - Center of Orientation to the Family - and residing in Salvador, state of Bahia, Brazil, who showed emotional problems associated with family life. Semi-structured interviews with the participants, together with the participants' attendance reports, provided the empirical basis for the study. The analysis of the collected material was made by grouping the contents into subject themes. The theme that stood out - fear of repeating their mothers' life history - unfolded into: absence of paternal figure; lack of credibility concerning the male figure; sexuality problems and conflicts with the mother. These youths' struggles focused preferably on study and professional targets; the young women felt responsible for sharing family expenses, and often took roles belonging to their parents. Overloaded by these situations and feeling incapable of dealing with them, these youths were seriously hit by the incidence of psychosomatic symptoms that exposed the dramatic conflicts they were living with. Hence, it is concluded that the liberalization possibility open to new generations within an urban and individualistic society conflicts, in these cases, with the still traditional ideals where the standards and beliefs point towards a logic of reciprocity and solidarity of kinship ties.
\end{abstract}

Key words: Differentiation. Repetition. Mother/daughter relationship. Youths. Family conflicts. 


\section{REFERÊNCIAS}

1. Cerveny CMO. A família como modelo: desconstruindo a patologia. Campinas: Livro Pleno; 2000.

2. Bowen M. Family therapy in clinical practice. Nova York: J. Aronson; 1978.

3. Carter B, Goldrick M. As mudanças no ciclo de vida familiar: uma estrutura para a terapia familiar. $2^{\mathrm{a}}$ ed. Porto Alegre: Artes Médicas; 1995.

4. Eliacheff C, Heinich N. Mães-filhas: uma relação a três. São Paulo: Martins Fontes; 2004.

5. Sarti CA. Família e individualidade: um problema moderno. In: Carvalho MCB, organizador. A família contemporânea em debate. São Paulo: EDUC/Cortez; 2002. p. 39-49.

6. Aberastury A. Adolescência. Porto Alegre: Artes Médicas; 1986.

7. Griffa MC, Moreno JE. Chaves para a psicologia do desenvolvimento: adolescência, vida adulta, velhice. São Paulo: Ed. Paulinas; 2001. v. 2.

8. Benevides MV. Conversando com os jovens sobre direitos humanos. In: Novaes R, Vannuchi P, organizadores. Juventude e sociedade: trabalho, educação, cultura e participação. São Paulo: Fundação Perseu Abramo; 2004. p. 275-303.

9. Castro MG. Políticas públicas por identidades e de ações afirmativas: acessando gênero e raça, na classe, focalizando juventudes. In: Novaes R, Vannuchi P, organizadores. Juventude e sociedade: trabalho, educação, cultura e participação. São Paulo: Fundação Perseu Abramo; 2004. p. 275-303.

10. Costa J. Perspectivas da juventude na sociedade de mercado. In: Novaes R, Vannuchi P, organizadores. Juventude e sociedade: trabalho, educação, cultura e participação. São Paulo: Fundação Perseu Abramo; 2004. p. 75-88.

11. Pochmann M. Juventude em busca de novos caminhos no Brasil. In: Novaes R, Vannuchi P, organizadores. Juventude e sociedade: trabalho, educação, cultura e participação. São Paulo: Fundação Perseu Abramo; 2004. p. 217-41.

12. Unesco. Políticas públicas de/para/com juventudes. Brasília (DF); 2004.

13. Berenstein I. Problemas familiares contemporâneos o situaciones familiares actuales: invariância y novedad. Psicol USP. 2002;13(2):15-25.

14. Kagitcibasi C. Autonomy and relatedness in cultural context: implications for self and family. J Cross Cult Psychol. 2005;36(4):40322.

15. Bilac ED. Sobre as transformações das estruturas familiares no Brasil: notas muito preliminares. In: Ribeiro I, Ribeiro AC, organizadores. Família em processos contemporâneos: inovações culturais na sociedade brasileira. São Paulo: Loyola; 1995. p. 43-61.

16. Petrini JC. Pós-modernidade e família: um itinerário de compreensão. Bauru: EDUSC; 2003.

17. Fonseca C. Família, fofoca e honra: etnografia de relações de gênero e violência em grupos populares. Porto Alegre: Ed. Universidade/UFRGS; 2000.

18. Sarti CA. Família patriarcal entre os pobres urbanos? Cad Pesqui. 1992;82:37-41.

19. Bastos ACS. Modos de partilhar: a criança e o cotidiano da família. Taubaté: Cabral; 2001.

20. Fonseca C. Mãe é uma só?: reflexões em torno de alguns casos brasileiros. Psicol USP. 2002;13(2):49-68.

21. Forbes J. Por que Daniele matou Eduardo: o fenômeno das agressões inusitadas é a doença de um mundo que descartou a figura do pai. O Estado de São Paulo. 2005 abr 17;Caderno Aliás:J3.

22. Sarti CA. Algumas questões sobre família e políticas sociais. In: Jacquet C, Costa LF, organizadores. Família em mudança. São Paulo: Companhia Ilimitada; 2004. p. 193213.

23. Berquó E. Arranjos familiares no Brasil: uma visão demográfica. In: História da vida privada no Brasil; 1998. v. 4, p. 411-37.

24. Sarti CA. O jovem na família: o outro necessário. In: Novaes R, Vannuchi P, organizadores. Juventude e sociedade: trabalho, educação, cultura e participação. São Paulo: Fundação Perseu Abramo; 2004. p.115-29.

25. Ferreira $\mathrm{ABH}$. Minidicionário da língua portuguesa. Rio de Janeiro: Nova Fronteira; 1985.

26. Nichols MP, Schwartz RC. Terapia familiar: conceitos e métodos. $3^{\text {a }}$ ed. Porto Alegre: Artes Médicas; 1998.

Recebido em: 17/09/2006 Modificado em: 23/09/2006 Aprovado em: 30/09/2006 


\section{Roteiro de Entrevista}

Ficha $n^{\circ}$ :

Nome:

Encaminhado por:

\section{Área Familiar}

Estado civil:

Idade:

Situação financeira:
Profissional:

Cônjuge:

Escolaridade:

Situação de moradia:
Data: / /

Pedido principal:

família de origem).

\section{Relacionamento familiar}

\section{Área Escolar}

Nível de instrução:

Estuda atualmente?

Parou ou concluiu?

Rendimento escolar (repetências, dificuldades de aprendizagem e a que atribui).

Deseja retornar aos estudos (o que dificulta e o que estimula)?

\section{Área Social}

Descrição da vida social (Como é seu círculo de amizades? Relacionamentos?)

Lazer (O que entende por lazer? Que tipo de atividades prefere fazer para se distrair?).

\section{Área Religiosa}

Possui religião?

Freqüenta?

É a mesma da família?

Em caso negativo, qual é e como lidam com esta diferença?

\section{Área de Saúde}

Saúde pessoal (como está atualmente, internações, cirurgias, acidentes, abortos, dores constantes, alterações no sono, uso de medicações de uso constante, adicção).

Saúde familiar (doenças, quais, quem, há quanto tempo, mortes, etc. )

Convênio médico: Referência médica/ambulatorial/hospitalar:

\section{Área Profissional}

Atividade profissional que exerce no momento e há quanto tempo (remunerada ou não).

Relacionamento com colegas e chefia

Nível de satisfação.

Desempregado?

Há quanto tempo?

O que gostaria de fazer?

\section{Rede de Apoio}

Com quem pode contar?

Instituições públicas e privadas a que recorre (impressões das mesmas e pessoas de referência).

\section{Auto - Percepção}

Como é seu temperamento (características)?

Como você se vê como pessoa (aceitação destas características)?

Observações Finais Sobre a Entrevista. 


\section{QUADRO I - CONTEXTO FAMILIAR}

\begin{tabular}{|c|c|c|c|c|c|}
\hline Nome & Idade & Escolaridade & Contexto familiar & Sit. financeira & Auto percepção \\
\hline Dulce & 21 & Universitária & $\begin{array}{l}\text { Reside c/ pais, e } 2 \text { irmãs mais } \\
\text { novas; } \\
\text { Falta de apoio da família }\end{array}$ & $\begin{array}{l}\text { Estável, pai comerciante } \\
\text { no bairro }\end{array}$ & $\begin{array}{l}\text { Ansiosa, } \\
\text { fala alto. }\end{array}$ \\
\hline Dayane & 21 & Universitária & $\begin{array}{l}\text { Mora com pais e irmã; } \\
\text { Muito dependentes uns dos } \\
\text { outros, fechados. }\end{array}$ & $\begin{array}{l}\text { Ela e pai mantêm a casa, são } \\
\text { assalariados; situação crítica. }\end{array}$ & $\begin{array}{l}\text { Calma, tímida, } \\
\text { ansiosa e } \\
\text { insegura. }\end{array}$ \\
\hline Suzie & 28 & Universitária & $\begin{array}{l}\text { Mora com mãe, padrasto, irmã, } \\
\text { enteado. Mãe dominadora. Pai } \\
\text { falecido. }\end{array}$ & Dificuldades sérias & $\begin{array}{l}\text { Calma, } \\
\text { introvertida, } \\
\text { ingênua. }\end{array}$ \\
\hline Adélia & 28 & Universitária & $\begin{array}{l}\text { Mora com mãe, padrasto, irmã. } \\
\text { Conflitos entre eles. } \\
\text { Pai no interior, doente. }\end{array}$ & $\begin{array}{l}\text { Estável; família de baixa renda, } \\
\text { empregados. }\end{array}$ & $\begin{array}{l}\text { Gosta de ficar } \\
\text { só, desconfiada. }\end{array}$ \\
\hline Aparecida & 19 & Universitária & $\begin{array}{l}\text { Mora c/ mãe. Parentes em mesmo } \\
\text { sobrado. } \\
\text { Pai vivo, distante. }\end{array}$ & Estável; família de baixa renda & Acha-se egoísta \\
\hline Joana & 26 & Universitária & $\begin{array}{l}\text { Divide-se entre casa da avó e de } \\
\text { religiosas. } \\
\text { Família ampliada reside no } \\
\text { mesmo terreno. } \\
\text { Tem } 3 \text { irmãos. } \\
\text { Não conheceu pai. }\end{array}$ & $\begin{array}{l}\text { Vivem em função da escola que } \\
\text { avó tem em casa. Família } \\
\text { carente. }\end{array}$ & $\begin{array}{l}\text { Impaciente, } \\
\text { ansiosa. }\end{array}$ \\
\hline Mary & 22 & Universitária & $\begin{array}{l}\text { Mora com os pais, e irmã mais } \\
\text { nova. } \\
\text { Conflitos entre eles. } \\
\text { Pai alcoolista. } \\
\text { Irmã mais velha revoltada, } \\
\text { mora fora. }\end{array}$ & $\begin{array}{l}\text { Dificílima. Pais desempregados. } \\
\text { Mantém a família. }\end{array}$ & $\begin{array}{l}\text { Intolerante. } \\
\text { Critica com } \\
\text { tudo e consigo } \\
\text { mesma. }\end{array}$ \\
\hline
\end{tabular}

Fonte: Entrevistas realizadas no COF - Salvador-BA, no período entre 2000 e 2005. 